\title{
Utility of arterial blood gas, CBC, biochemistry and cardiac hormones as evaluation parameters of cardiovascular disease in nonhuman primates
}

\author{
Shunya NAKAYAMA ${ }^{1,2)}$, Hiroshi KOIE ${ }^{1)}$, Kiichi KANAYAMA ${ }^{1)}$, Yuko KATAKAI ${ }^{3)}$, \\ Yasuyo ITO-FUJISHIRO ${ }^{1,2)}$, Tadashi SANKAI ${ }^{2)}$, Yasuhiro YASUTOMI ${ }^{2,4)}$ and \\ Naohide AGEYAMA ${ }^{2) *}$ \\ ${ }^{1)}$ Nihon University, College of Bioresource Science, Kanagawa 252-0880, Japan \\ ${ }^{2)}$ Tsukuba Primate Research Center, National Institutes of Biomedical Innovation, Health and Nutrition, \\ Ibaraki 305-0843, Japan \\ ${ }^{3)}$ The Corporation for Production and Research of Laboratory Primates, Ibaraki 305-0003, Japan \\ ${ }^{4)}$ Mie University Graduate School of Medicine, Department of Molecular and Experimental Medicine, \\ Mie 514-8507, Japan
}

J. Vet. Med. Sci.

80(7): 1165-1173, 2018

doi: 10.1292/jvms.18-0124

Received: 8 March 2018

Accepted: 24 May 2018

Published online in J-STAGE:

11 June 2018
ABSTRACT. Cardiovascular disease (CVD) has a tremendous impact on the quality of life of humans. While experimental animals are valuable to medical research as models of human diseases, cardiac systems differ widely across various animal species. Thus, we examined a CVD model in cynomolgus monkeys. Laboratory primates are precious resources, making it imperative that symptoms of diseases and disorders are detected as early as possible. Thus, in this study we comprehensively examined important indicators of CVD in cynomolgus monkeys, including arterial blood gas, complete blood count (CBC), biochemistry and cardiac hormones. The control group included 20 healthy macaques showing non-abnormal findings in screening tests, whereas the CVD group included 20 macaques with valvular disease and cardiomyopathy. An increase of red blood cell distribution width was observed in the $\mathrm{CBC}$, indicating chronic inflammation related to CVD. An increase of $\mathrm{HCO}_{3}$ was attributed to the correction of acidosis. Furthermore, development of the CVD model was supported by significant increases in natriuretic peptides. It is suggested that these results indicated a correlation between human CVD and the model in monkeys. Moreover, blood tests including arterial blood gas are non-invasive and can be performed more easily than other technical tests. CVD affected animals easily change their condition by anesthesia and surgical invasion. Pay attention to arterial blood gas and proper respond to their condition are important for research. This data may facilitate human research and aid in the management and veterinary care of nonhuman primates.

KEY WORDS: arterial blood gas, cardiac hormone, cardiovascular disease, complete blood count, nonhuman primate

Cardiovascular disease (CVD) can be diagnosed using several blood exams, in addition to technical examinations such as echocardiography, X-ray, and electrocardiogram (ECG). Complete blood count (CBC), biochemical parameters, and arterial and venous blood gas measurements are major clinical diagnostic tools. Arterial blood gas is a particularly important parameter because the cardiovascular system is closely related to the respiratory system. In addition, the oxygenation of blood and the excretion of carbon dioxide and other gases can be determined directly from arterial blood gas. Diagnosis can be performed with each of the various exams; however, an accurate diagnosis can be made earlier when a combination of several exams is used. Arterial blood gas is the most sensitive diagnostic, and is often used during operative anesthesia. Since CVD often results in irreversible dysfunction, utilization of the arterial blood gas test to obtain earlier estimates of CVD parameters will add the utility of experimental animals for clinical and medical treatment.

In research of cardiovascular systems, nonhuman primates (NHPs) are especially appropriate for the development of the medical sciences $[1,2,6,26,28]$. The genetics, physiology and anatomy of NHPs are very similar to humans, and NHPs are susceptible to

*Correspondence to: Ageyama, N.: ageyama@nibiohn.go.jp

O2018 The Japanese Society of Veterinary Science

This is an open-access article distributed under the terms of the Creative Commons Attribution Non-Commercial No Derivatives (by-nc-nd) License. (CC-BY-NC-ND 4.0: https://creativecommons.org/licenses/by-nc-nd/4.o/) 
Table 1. Physical characteristics of the cynomolgus monkeys

\begin{tabular}{llccc}
\hline & Sex & N & $\begin{array}{c}\text { Age } \\
\text { Mean } \pm \text { SD }\end{array}$ & $\begin{array}{c}\text { Body weight } \\
\text { Mean } \pm \text { SD }\end{array}$ \\
\hline Control & Male & 3 & $28.67 \pm 4.03$ & $6.12 \pm 1.61$ \\
& Female & 17 & $19.76 \pm 6.49$ & $4.02 \pm 0.70$ \\
DCM & Male & 2 & $29.50 \pm 1.50$ & $6.20 \pm 0.10$ \\
& Female & 2 & $18.50 \pm 1.50$ & $3.79 \pm 1.33$ \\
VD & Male & 4 & $24.25 \pm 6.18$ & $5.55 \pm 0.91$ \\
& Female & 11 & $29.73 \pm 5.71$ & $3.63 \pm 0.94$ \\
\hline
\end{tabular}

DCM, dilated cardiomyopathy; VD, valvular heart disease.

many of the same diseases [7, 12-15, 20, 22]. However, only partial information for many reference values is available for NHPs, thus medical researchers commonly rely on data from other animals (mice, rats, rabbits, dogs and cats) for use as reference values for humans in their studies.

Currently, common methods used to diagnose CVD include ECG, echocardiography and analysis of cardiac hormones. Echocardiography is a particularly sensitive technique to diagnose CVDs; however, it is highly technical and requires considerable skill. Laboratory primates are precious resources, thus, it is necessary to detect symptoms of diseases and disorders as early as possible. In medical research, a high skill level is required for observations and treatments, while simple and easy methods are important to ensure proper management of animals. This study aims to investigate the applicability of arterial blood gases and other blood exams as evaluation parameters. In the future, the increasingly common use of arterial blood gas as a measurement parameter will enable the management of animals with conditions such as CVDs. Additionally, clarification of the utility of the arterial blood gas test would allow its application to various studies such as stable surgical anesthesia.

The Tsukuba Primate Research Center (National Institutes of Biomedical Innovation Health and Nutrition) maintains approximately 1,400 cynomolgus monkeys in a closed environment for biomedical research, and is the largest experimental colony in Japan. The macaques are used for numerous research projects at our institution, including vaccinology, infectious disease, gene therapy, regenerative medicine, and aging studies. Furthermore, this colony is being used in advanced clinical studies from around the world $[1,2,6,13,20,26,28]$.

Especially, proper management that referred to various blood test is necessary to obtain ideal results in medical science research for the CVD affected monkeys. From the viewpoint of animal welfare, these proper management is indispensable in using the experimental animals. Although it was known that CVD affected animals have high risk for anesthesia and surgical invasion, but there has been not reported in cynomolgus monkeys. This study is the first report to comprehensively examine important indicators of CVD in cynomolgus monkeys, including arterial blood gas, CBC, biochemistry and cardiac hormones. Thus, it is the first report to investigate the method of management for CVD affected monkeys from the findings of various blood test in normal and CVD affected monkeys. These results could be highly applicable to the stable management and maintenance of NHPs.

\section{MATERIALS AND METHODS}

\section{Animals}

Forty cynomolgus monkeys (10 years and older) were used for this study, all of which were bred at the Tsukuba Primate Research Center and housed under a consistent environment. Specifically, the animals were individually housed in stainless steel cages at 23 to $27^{\circ} \mathrm{C}, 50$ to $70 \%$ humidity, 12 air changes $/ \mathrm{hr}$, and a 12/12-hr light/dark cycle, and were fed $70 \mathrm{~g}$ of commercial monkey chow (CMK-2; CLEA Japan, Inc., Tokyo, Japan) and $200 \mathrm{~g}$ of fruit daily. The 20 healthy monkeys (3 males, 17 females) in the control group were from 11 to 35 years old (Table 1), and received medical examinations in our facility. The control animals did not have abnormalities in chest auscultation, ECG, chest X-ray examination and echocardiographic examination. Additionally, no underlying diseases or abnormalities in appetite and behavior were observed in the control group. The CVD group included 20 monkeys (6 male, 14 female) from 17 to 35 years old (Table 1). The animals in the CVD group appeared normal, with no obvious abnormalities in appetite or behavior, and medical treatment was not required. However, the CVD group exhibited abnormalities in many parameters, including chest auscultation, ECG, chest X-ray examination, and echocardiographic examination. The CVD animals included 16 cases of valvular heart disease (VD), which is characterized by regurgitation and stenosis of the aortic valve and pulmonary valve (Fig. 1A), and 4 cases of dilated cardiomyopathy (DCM; Fig. 1B). However, clinical symptoms were not observed, indicating that the CVD grade was in the early to middle period. Based on the cardiovascular and pathological diagnoses, CVD animals were further separated into the VD group and the DCM group (Fig. 1). Additionally, the control group was conducted as age-matched controls, because the CVD group did not contain young animals less than 17 years old. Moreover, because of the characteristics of the breeding colony at our facility, there were a limited number of male monkeys included in this study.

This study was conducted according to the Rules for Animal Care and Management of the Tsukuba Primate Center, the Guiding Principles for Animal Experiments Using Nonhuman Primates formulated by the Primate Society of Japan and the Institute for Laboratory Animal Research (ILAR) Guide for Care and Use of Laboratory Animals [8-10]. The Animal Welfare and Animal Care Committee of the National Institutes of Biomedical Innovation Health and Nutrition (NIBIOHN, Osaka, Japan) approved the experimental protocol. 

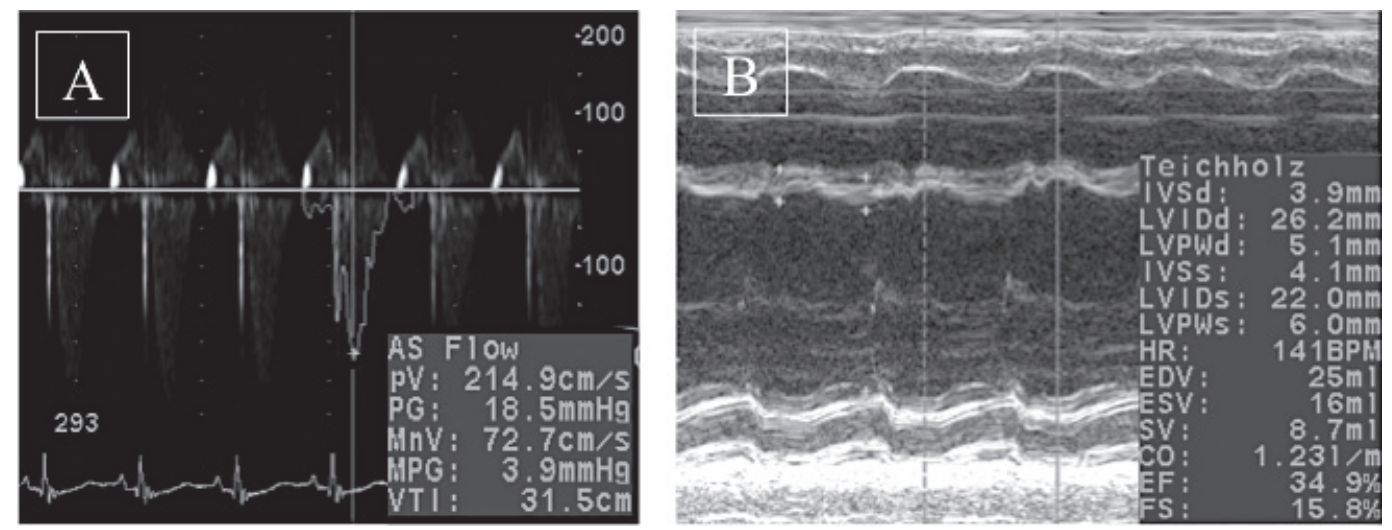

Fig. 1. Echocardiography of the nonhuman primate CVD model. Echocardiographs of aortic valve stenosis (A) and dilated cardiomyopathy (B) are shown. (A) The subject was 17 years old and weighed $2.11 \mathrm{~kg}$. This animal was diagnosed with aortic stenosis because of the rapid turbulence in the aortic valve from stenosis. (B) The subject was 31 years old and weighed $6.1 \mathrm{~kg}$. This animal was diagnosed with dilated cardiomyopathy, characterized by dilated ventricles and diffuse left ventricle hypokinesis. However, no abnormalities in behavior caused by CVD were observed in each animal. The macaque CVD model shows similar findings in echocardiography.

\section{Blood sample collection}

Blood samples were collected from the femoral or caudal artery while the monkeys were under ketamine sedation $(5-10 \mathrm{mg} / \mathrm{kg}$ IM, Ketalar; Daiichi Sankyo Propharma, Tokyo, Japan). For blood sampling, the artery was identified by palpating the pulse and the needle was inserted into femoral artery. The collected blood was immediately examined for blood gases. $\mathrm{SpO}_{2}$ values were used to confirm arterial blood gas and the blood gas values were recorded. CBC analysis samples were collected in K2-EDTA tubes. The human brain natriuretic peptide (hBNP) analysis was performed on chilled K2-EDTA, and human atrium natriuretic peptide (hANP) analysis was performed on aprotinin plasma. Biochemical analyzes were performed on serum samples.

\section{Blood analysis}

We analyzed arterial blood gas, CBC, biochemistry and cardiac hormones. An auto-analyzer (Rapid Lab 348; Siemens, Berlin, Germany) was used to evaluate blood gas parameters, including $\mathrm{pH}, \mathrm{pCO}_{2}, \mathrm{pO}_{2}$, sodium ion $\left(\mathrm{Na}^{+}\right)$, potassium ion $\left(\mathrm{K}^{+}\right)$, calcium ion $\left(\mathrm{Ca}^{++}\right), \mathrm{HCO}_{3}$, base excess (BE), $\mathrm{CO}_{2}$ concentration $\left(\mathrm{ctCO}_{2}\right), \mathrm{Ca}^{++}(7.4)$ and $\mathrm{O}_{2}$ saturation $(\mathrm{SAT})$. The corrected $\mathrm{HCO}_{3}\left(\mathrm{cHCO}_{3}\right)$ and anion gap were calculated in reference to previous reports $[15,20]$. CBC values were analyzed using a $\mathrm{CBC}$ auto-analyzer (KX-21; SYSMEX, Kobe, Japan). White blood cell count (WBC), red blood cell count (RBC), hemoglobin (HGB), hematocrit (HCT), mean corpuscular volume (MCV), mean corpuscular hemoglobin (MCH), mean corpuscular hemoglobin concentration (MCHC), platelets (Plt), red blood cell distribution width (RDW), platelet cell distribution width (PDW) and mean platelet volume (MPV) were determined. Biochemical parameters were analyzed using an auto-analyzer (AU480; Beckman Coulter, CA, U.S.A.). The biochemical parameters determined were total protein (TP), albumin (ALB), albumin-globulin ratio (A/G), blood urea nitrogen (BUN), glucose (GLU), aspartate aminotransferase (AST), alanine aminotransferase (ALT), creatinine phosphokinase (CPK), lactate dehydrogenase (LDH), C-reactive protein (CRP), serum creatinine (CRE), gamma-glutamyl transferase (GGT), chloride. $\mathrm{The} \mathrm{Na} / \mathrm{Cl}$ ratio was calculated from these values. The cardiac hormones evaluated were hANP and hBNP, which were analyzed using an auto-enzyme immunoassay device (AIA-360; Tosoh Corp., Tokyo, Japan).

\section{Statistical analysis}

A two-tailed Welch's $t$-test was employed to compare mean values obtained from the CVD and control groups. $P$ values $\leq 0.05$ were considered statistically significant. A one-tailed test was performed to compare the reactive items such as the cardiac hormone levels and CRP. A one-way analysis of variance (ANOVA) and Tukey's correction were used for analysis of three groups in this study. All statistical analyzes were performed with EZR (Saitama Medical Center, Jichi Medical University, Saitama, Japan), which is a graphical user interface for R (The R Foundation for Statistical Computing, Vienna, Austria). More precisely, it is a modified version of $\mathrm{R}$ commander designed to add statistical functions frequently used in biostatistics [11].

\section{RESULTS}

The results of the blood analyzes of the control and CVD groups are presented in Tables 2-7.

\section{Arterial blood gas}

Several significant differences were observed in the disease group (Tables 2 and 3). Significantly higher $\mathrm{pCO}_{2}$ levels were observed, and $\mathrm{ctCO}_{2}$ showed a tendency to be increased. While $\mathrm{HCO}_{3}$ was not significantly altered, $\mathrm{cHCO}_{3}$ was significantly elevated. $\mathrm{CHCO}_{3}$ has been used in human clinical medicine and is applied to the $\mathrm{HCO}_{3}$ calculation formula. The electrolyte analysis 
Table 2. Results of the arterial blood gas analysis

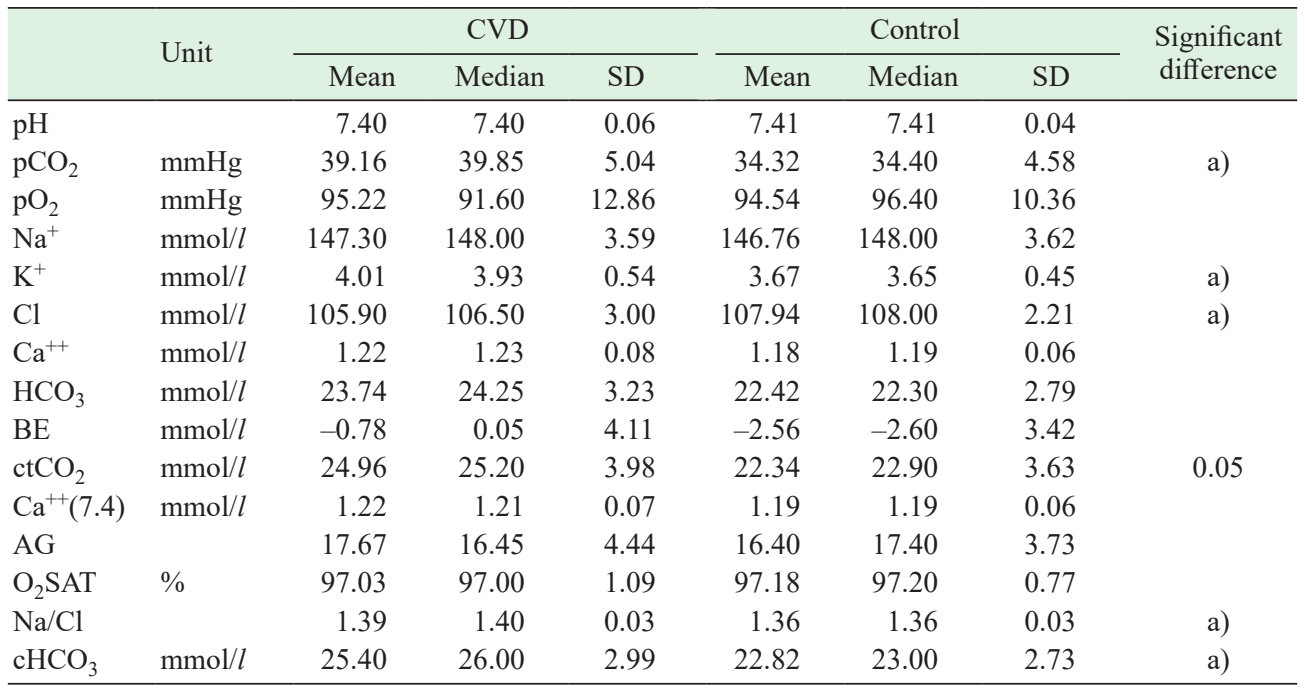

a) $P<0.05$.

Table 3. Results of the arterial blood gas analysis

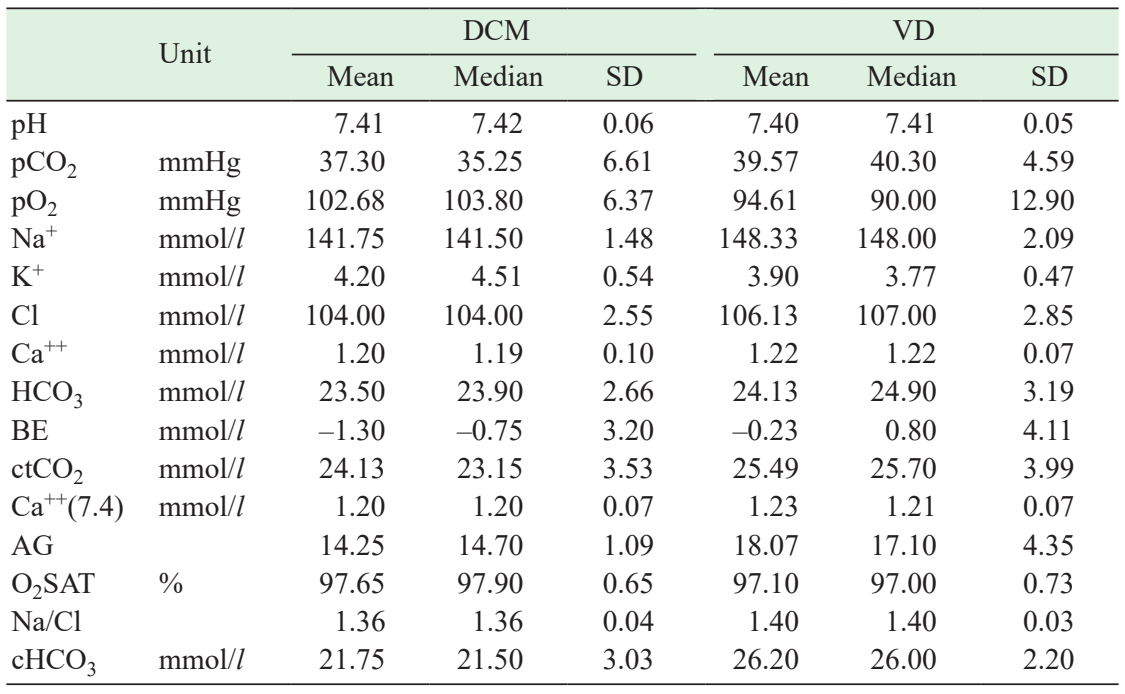

indicated significant increases of potassium, chloride and the $\mathrm{Na} / \mathrm{Cl}$ ratio. Additionally, there were significant increases of $\mathrm{cHCO}_{3}$, $\mathrm{pCO}_{2}$ and the $\mathrm{Na} / \mathrm{Cl}$ ratio in the VD group (ANOVA). In particular, $\mathrm{cHCO}_{3}$ showed clear differences (Fig. 2).

\section{$C B C$}

The results of the $\mathrm{CBC}$ analysis indicated that a few parameters were significantly altered in the disease group (Tables 4 and 5). Specifically, significantly increased RDW and a tendency for decreased $\mathrm{MCHC}$ were observed. In addition, ANOVA revealed significant differences in RDW (Fig. 3A,) MCV (Fig. 3B), MCH (Fig. 3C) and MCHC (Fig. 3D). Further, there were significant increases in $\mathrm{MCV}, \mathrm{MCH}$ and $\mathrm{MCHC}$ in the DCM group (Fig. 3B-D).

\section{Biochemistry and cardiac hormones}

The CRP value was increased in the CVD group (Tables 6 and 7). Analysis of cardiac hormones indicated that hANP was significantly increased in the CVD group. Although hBNP did not significantly differ, it showed a tendency to increase. Furthermore, in the results of the statistical analysis for the three group, the DCM group showed a significant increase in potassium, hANP and hBNP (Fig. 4A and 4B). 

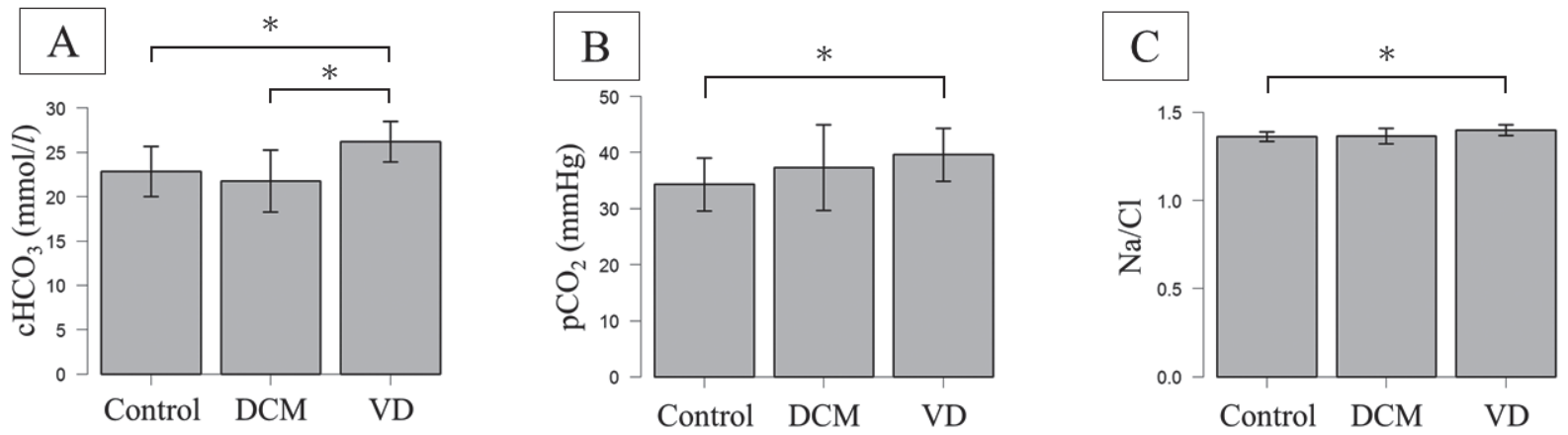

Fig. 2. Analysis of arterial blood gas parameters in $\mathrm{CVD}$ subgroups. $\mathrm{CHCO}_{3}$ and the $\mathrm{Na} / \mathrm{Cl}$ ratio were especially elevated in valvular heart disease (A, B). Among heart disease groups, valvular heart disease is known to affect metabolism in particular. * $P<0.05$, one-way ANOVA and Tukey's correction.

Table 4. Results of CBC analysis

\begin{tabular}{|c|c|c|c|c|c|c|c|c|}
\hline & \multirow{2}{*}{ Unit } & \multicolumn{3}{|c|}{ CVD } & \multicolumn{3}{|c|}{ Control } & \multirow{2}{*}{$\begin{array}{l}\text { Significant } \\
\text { difference }\end{array}$} \\
\hline & & Mean & Median & SD & Mean & Median & SD & \\
\hline WBC & $10^{2} / \mu l$ & 92.21 & 96.00 & 30.91 & 86.73 & 91.00 & 27.24 & \\
\hline $\mathrm{RBC}$ & $10^{2} / \mu l$ & 687.53 & 674.00 & 89.62 & 673.55 & 673.50 & 93.04 & \\
\hline HGB & $\mathrm{g} / \mathrm{d} l$ & 13.17 & 12.80 & 1.91 & 13.28 & 13.25 & 1.78 & \\
\hline HCT & $\%$ & 46.36 & 45.40 & 6.60 & 45.55 & 46.65 & 5.72 & \\
\hline $\mathrm{MCV}$ & $\mathrm{f} l$ & 67.59 & 67.00 & 5.59 & 67.83 & 67.75 & 2.86 & \\
\hline $\mathrm{MCH}$ & $p \mathrm{~g}$ & 19.23 & 18.70 & 2.07 & 19.78 & 19.45 & 1.34 & \\
\hline $\mathrm{MCHC}$ & $\mathrm{g} / \mathrm{d} l$ & 28.42 & 27.80 & 1.22 & 29.14 & 29.10 & 1.18 & 0.07 \\
\hline PLT & $10^{4} / \mu l$ & 33.25 & 31.70 & 8.50 & 33.53 & 30.95 & 13.16 & \\
\hline RDW & $\mathrm{f} l$ & 35.68 & 35.50 & 3.47 & 31.55 & 33.50 & 5.34 & a) \\
\hline PDW & $\mathrm{f} l$ & 11.72 & 11.60 & 1.52 & 11.82 & 11.00 & 2.03 & \\
\hline MPV & $\mathrm{f} l$ & 9.82 & 9.60 & 1.01 & 10.00 & 10.00 & 1.08 & \\
\hline
\end{tabular}

a) $P<0.05$. WBC, white blood cell count; RBC, red blood cell count; HGB, hemoglobin; HCT, hematocrit; $\mathrm{MCV}$, mean corpuscular volume; $\mathrm{MCH}$, mean corpuscular hemoglobin; $\mathrm{MCHC}$, mean corpuscular hemoglobin concentration; PLT, platelets; RDW, red blood cell distribution width; PDW, platelet cell distribution width; MPV, mean platelet volume.

Table 5. Results of $\mathrm{CBC}$ analysis

\begin{tabular}{|c|c|c|c|c|c|c|c|}
\hline & \multirow{2}{*}{ Unit } & \multicolumn{3}{|c|}{ DCM } & \multicolumn{3}{|c|}{ VD } \\
\hline & & Mean & Median & SD & Mean & Median & SD \\
\hline WBC & $10^{2} / \mu l$ & 108.25 & 109.50 & 37.50 & 85.64 & 95.50 & 26.89 \\
\hline $\mathrm{RBC}$ & $10^{2} / \mu l$ & 594.25 & 626.00 & 80.31 & 715.14 & 711.00 & 76.12 \\
\hline HGB & $\mathrm{g} / \mathrm{d} l$ & 13.10 & 14.00 & 2.58 & 13.23 & 12.80 & 1.73 \\
\hline HCT & $\%$ & 43.80 & 45.85 & 6.92 & 47.16 & 45.55 & 6.54 \\
\hline $\mathrm{MCV}$ & $\mathrm{f} l$ & 73.45 & 73.55 & 2.33 & 65.93 & 65.05 & 5.31 \\
\hline $\mathrm{MCH}$ & $p \mathrm{~g}$ & 21.85 & 22.30 & 1.49 & 18.51 & 18.25 & 1.64 \\
\hline $\mathrm{MCHC}$ & $\mathrm{g} / \mathrm{d} l$ & 29.73 & 30.45 & 1.47 & 28.09 & 27.80 & 0.89 \\
\hline PLT & $10^{4} / \mu l$ & 37.60 & 31.55 & 10.80 & 31.09 & 31.75 & 6.55 \\
\hline RDW & $\mathrm{f} l$ & 34.93 & 36.00 & 2.93 & 35.89 & 34.95 & 3.70 \\
\hline PDW & $\mathrm{f} l$ & 12.45 & 12.15 & 0.87 & 11.50 & 11.25 & 1.65 \\
\hline MPV & $\mathrm{f} l$ & 10.63 & 10.45 & 0.83 & 9.56 & 9.40 & 0.96 \\
\hline
\end{tabular}

WBC, white blood cell count; RBC, red blood cell count; HGB, hemoglobin; HCT, hematocrit; $\mathrm{MCV}$, mean corpuscular volume; $\mathrm{MCH}$, mean corpuscular hemoglobin; $\mathrm{MCHC}$, mean corpuscular hemoglobin concentration; PLT, platelets; RDW, red blood cell distribution width; PDW, platelet cell distribution width; MPV, mean platelet volume. 

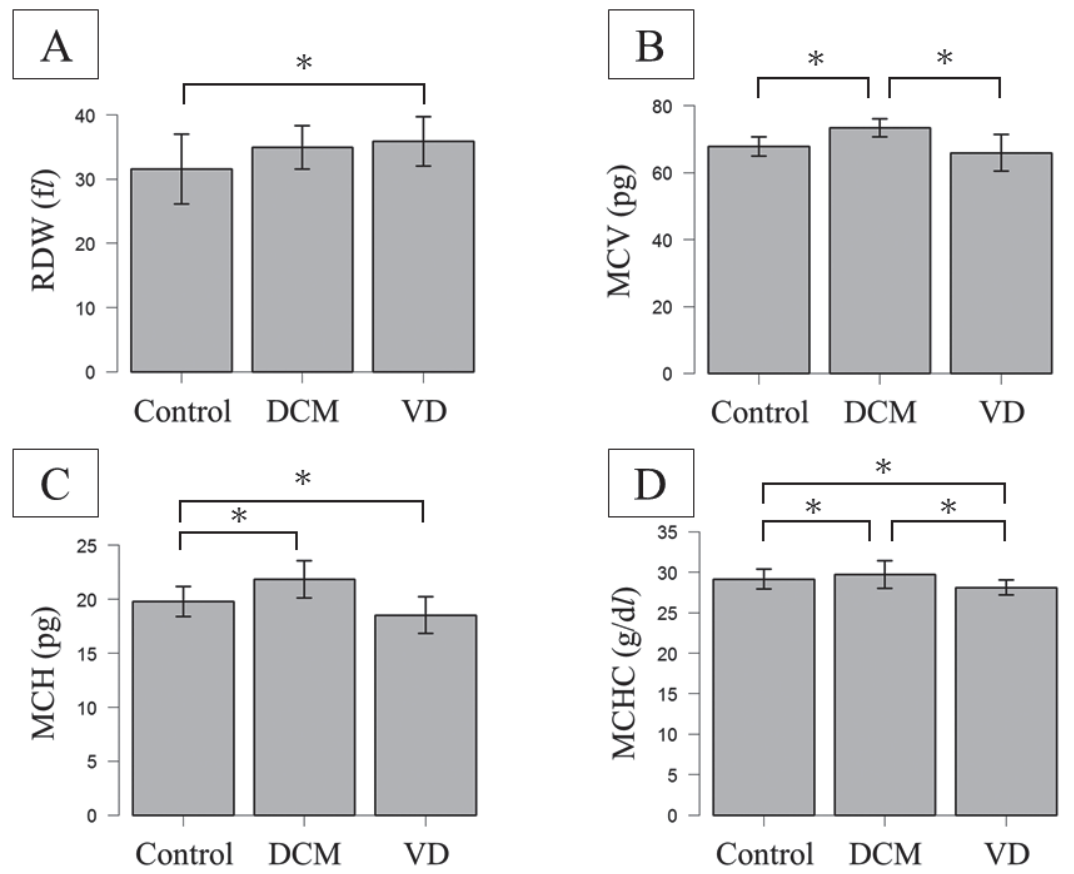

Fig. 3. Analysis of CBC parameters in CVD subgroups. Both CVD subgroups showed similar increases in RDW (A). MCHC was decreased in the VD group (D), and MCV and MCH were increased in the DCM group (B, C). ${ }^{*} P<0.05$, one-way ANOVA and Tukey's correction.

Table 6. Results of biochemical analyses

\begin{tabular}{|c|c|c|c|c|c|c|c|c|}
\hline & \multirow{2}{*}{ Unit } & \multicolumn{3}{|c|}{ CVD } & \multicolumn{3}{|c|}{ Control } & \multirow{2}{*}{$\begin{array}{l}\text { Significant } \\
\text { difference }\end{array}$} \\
\hline & & Mean & Median & SD & Mean & Median & SD & \\
\hline TP & $\mathrm{g} / \mathrm{d} l$ & 7.30 & 7.40 & 0.58 & 7.35 & 7.25 & 0.53 & \\
\hline ALB & $\mathrm{g} / \mathrm{d} l$ & 3.77 & 3.90 & 0.60 & 3.99 & 3.95 & 0.23 & \\
\hline $\mathrm{A} / \mathrm{G}$ & & 1.12 & 1.10 & 0.33 & 1.22 & 1.22 & 0.19 & \\
\hline BUN & $\mathrm{mg} / \mathrm{d} l$ & 16.18 & 15.75 & 3.72 & 16.40 & 15.65 & 2.98 & \\
\hline GLU & $\mathrm{mg} / \mathrm{d} l$ & 70.30 & 64.50 & 26.72 & 60.25 & 60.00 & 19.18 & \\
\hline AST & $\mathrm{IU} / l$ & 49.65 & 49.50 & 14.18 & 46.65 & 44.00 & 14.02 & \\
\hline ALT & $\mathrm{IU} / l$ & 76.85 & 68.00 & 48.53 & 89.40 & 62.50 & 70.14 & \\
\hline CPK & $\mathrm{IU} / l$ & 449.40 & 185.00 & 685.89 & 240.45 & 219.50 & 111.13 & \\
\hline LDH & $\mathrm{IU} / \mathrm{l}$ & $1,032.05$ & $1,069.50$ & 465.95 & 879.50 & 843.00 & 375.65 & \\
\hline CRP & $\mathrm{mg} / \mathrm{d} l$ & 0.32 & 0.14 & 0.53 & 0.08 & 0.08 & 0.04 & a) \\
\hline CRE & $\mathrm{mg} / \mathrm{d} l$ & 0.55 & 0.50 & 0.20 & 0.65 & 0.60 & 0.18 & \\
\hline GGT & $\mathrm{IU} / l$ & 73.00 & 70.00 & 30.27 & 60.33 & 56.00 & 19.92 & \\
\hline hANP & $p \mathrm{~g} / \mathrm{ml}$ & 78.24 & 58.15 & 104.70 & 27.12 & 24.40 & 9.34 & a) \\
\hline hBNP & $p \mathrm{~g} / \mathrm{ml}$ & 20.23 & 4.36 & 41.43 & 4.95 & 4.00 & 2.88 & 0.06 \\
\hline
\end{tabular}

a) $P<0.05$. TP, total protein; ALB, albumin; $\mathrm{A} / \mathrm{G}$, albumin-globulin ratio; $\mathrm{BUN}$, blood urea nitrogen; GLU, glucose; AST, aspartate aminotransferase; ALT, alanine aminotransferase; CPK, creatinine phosphokinase; LDH, lactate dehydrogenase; CRP, C-reactive protein; CRE, serum creatinine; GGT, gamma-glutamyl transferase; hANP, human atrium natriuretic peptide; hBNP, human brain natriuretic peptide.

\section{DISCUSSION}

\section{Arterial blood gas}

None of the subjects in this study exhibited clinical symptoms accompanying CVD, nor were signs of respiratory dysfunction observed. However, $\mathrm{pCO}_{2}$ and $\mathrm{ctCO}_{2}$ increased in the CVD group (Table 2). It is reasonable to think that the $\mathrm{CO}_{2}$ levels were abnormal because the observed elevated values are also higher than the reported standard values [20]. We speculate that this might have been caused by pulmonary circulatory insufficiency, although this is not a clinical symptom, or the accumulation of liquid in the lung, or other unknown mechanisms. In addition, the increase of $\mathrm{cHCO}_{3}$ likely indicates metabolic acidosis (Fig. 2A). In human medicine, $\mathrm{CHCO}_{3}$ values have been used to accurately assess ionic dynamics when the anion gap is open $[12,25]$. In this study, 
Table 7. Results of biochemical analyses

\begin{tabular}{|c|c|c|c|c|c|c|c|}
\hline & \multirow{2}{*}{ Unit } & \multicolumn{3}{|c|}{ DCM } & \multicolumn{3}{|c|}{ VD } \\
\hline & & Mean & Median & SD & Mean & Median & SD \\
\hline TP & $\mathrm{g} / \mathrm{d} l$ & 7.00 & 7.10 & 0.81 & 7.35 & 7.40 & 0.49 \\
\hline ALB & $\mathrm{g} / \mathrm{d} l$ & 3.25 & 3.20 & 0.65 & 3.87 & 3.90 & 0.50 \\
\hline $\mathrm{A} / \mathrm{G}$ & & 0.95 & 0.94 & 0.35 & 1.15 & 1.11 & 0.32 \\
\hline BUN & $\mathrm{mg} / \mathrm{d} l$ & 18.00 & 17.65 & 3.07 & 15.41 & 14.80 & 3.64 \\
\hline GLU & $\mathrm{mg} / \mathrm{d} l$ & 86.75 & 91.50 & 28.70 & 64.53 & 62.00 & 24.45 \\
\hline AST & $\mathrm{IU} / l$ & 53.00 & 51.00 & 13.66 & 49.73 & 50.00 & 14.18 \\
\hline ALT & $\mathrm{IU} / \mathrm{l}$ & 73.00 & 80.00 & 33.30 & 74.53 & 61.00 & 51.65 \\
\hline CPK & $\mathrm{IU} / l$ & 781.00 & 361.00 & 847.31 & 377.13 & 166.00 & 630.36 \\
\hline LDH & $\mathrm{IU} / l$ & 870.00 & 793.50 & 345.96 & $1,106.60$ & $1,219.00$ & 479.86 \\
\hline CRP & $\mathrm{mg} / \mathrm{d} l$ & 0.69 & 0.23 & 0.87 & 0.24 & 0.14 & 0.36 \\
\hline CRE & $\mathrm{mg} / \mathrm{d} l$ & 0.55 & 0.65 & 0.21 & 0.55 & 0.50 & 0.20 \\
\hline GGT & $\mathrm{IU} / l$ & 55.00 & 55.00 & 15.00 & 75.53 & 70.00 & 31.93 \\
\hline hANP & $p \mathrm{~g} / \mathrm{m} l$ & 215.63 & 172.80 & 166.92 & 41.73 & 44.40 & 28.61 \\
\hline hBNP & $p \mathrm{~g} / \mathrm{m} l$ & 68.67 & 28.25 & 70.93 & 4.95 & 4.00 & 2.12 \\
\hline
\end{tabular}

TP, total protein; ALB, albumin; A/G, albumin-globulin ratio; BUN, blood urea nitrogen; GLU, glucose; AST, aspartate aminotransferase; ALT, alanine aminotransferase; CPK, creatinine phosphokinase; LDH, lactate dehydrogenase; CRP, C-reactive protein; CRE, serum creatinine; GGT, gamma-glutamyl transferase; hANP, human atrium natriuretic peptide; hBNP, human brain natriuretic peptide.
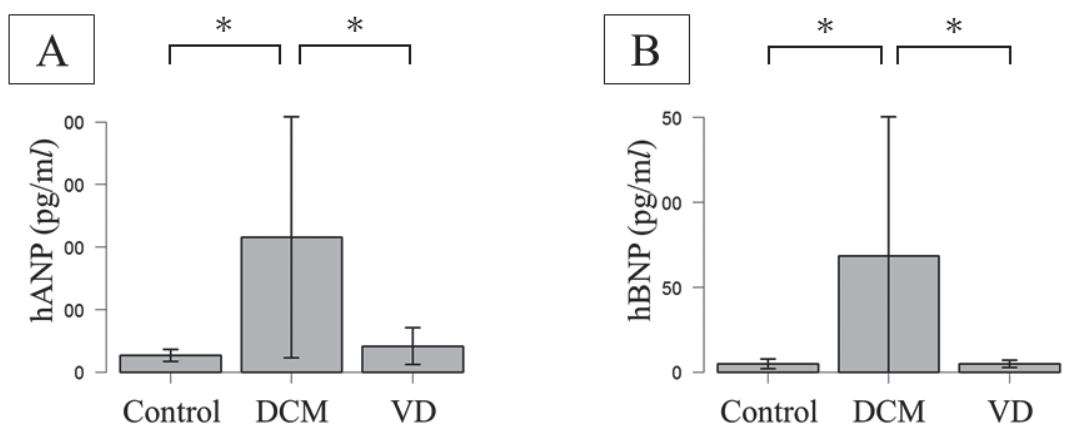

Fig. 4. Analysis of biochemical parameters in CVD subgroups. Compared with VD, DCM showed a clear increase in the hANP (A) and hBNP (B). This is related to the mechanism of cardiomyopathy, in which the disorder specifically occurs in the cardiac muscle. ${ }^{*} P<0.05$, one-way ANOVA and Tukey's correction.

corrected $\mathrm{HCO}_{3}$ values were calculated for all subjects. Furthermore, the increase in the Na/Cl ratio (Fig. 2C) suggests activation of the renin-angiotensin-aldosterone system (Fig. 2C) due to deterioration of circulations, which is associated with $\mathrm{cHCO}_{3}$ increases .

$C B C$

RDW in the CVD group was significantly increased in this study (Table 4). This result suggests that the decay and regeneration of erythrocytes occurred due to decreases in the deterioration of erythrocyte membrane stability resultant from chronic circulation reduction. RDW has been reported in reference to anemia; however, it is also known that RDW increases in association with CVDs, and its relevance and influence on prognosis has been discussed in recent human clinical reports [4, 5, 16, 23]. This study also suggested that RDW was significantly increased in the CVD group, reflecting the same pathological conditions as humans. MCHC showed a tendency to decrease in the CVD group (Fig. 3D). Since RDW was increased (Fig. 3A), it was thought that the observed decreases in $\mathrm{MCV}, \mathrm{MCH}, \mathrm{MCHC}$ were also caused by the collapse and regeneration of erythrocytes as a result of a chronic increase in erythrocyte load (Fig. 3B-D) [5].

\section{Biochemistry and cardiac hormones}

We observed several significant differences in biochemical parameters and cardiac hormones. In the CVD group, the potassium value in the electrolytes increased (Table 6). This is the same result obtained from blood gas analysis, and is related to cardiac load [23]. A few nonspecific effects, such as increased CRP were confirmed in the CVD group. These results suggest that the CVD group was prone to infection. However, it remains difficult to determine whether or not this is due to CVD. This also suggests that the cause of these changes is related to the observed increase in RDW. In other words, underlying chronic inflammation may have 
increased RDW, which signifies the presence of continuous intravascular inflammation [4, 16, 23]. Research on the relationship between RDW and CVD has been sparse, and the causal mechanism remains unknown. Thus, further research is necessary to elucidate the regulation of RDW in CVD [5]. In addition, the increase of CRP is suspected to involve other diseases such as myocardial damage. In humans and dogs, diagnostic applications to CRP of CVD were reported as high sensitive CRP in previous studies $[19,24]$. These reports suggest that the findings of this study show the similar mechanism.

Cardiac hormone tests showed significant increases of hANP, while hBNP showed a tendency to increase in the CVD group (Table 6). It is known that these values increase in humans and other animals with CVD [18, 21], and these results support the applicability of these parameters in the health management of nonhuman primates. Since this study confirmed the results in the previous reports, the clinical value of hANP and hBNP levels as indicators of CVD was reaffirmed.

\section{Insights derived from combining blood analyzes with pathological findings of CVD}

The blood parameters evaluated in this study were analyzed according to the pathological condition of CVD (Tables 3, 5 and 7). The CVD group included subjects with valvular dysfunction (aorta valve regurgitation, pulmonary valve regurgitation, mitral valve regurgitation, tricuspid valve regurgitation, aorta valve stenosis, pulmonary valve stenosis, mitral valve stenosis, tricuspid valve stenosis) and cardiomyopathy such as DCM. As mentioned above, these animals did not exhibit behavior abnormalities and the grade of CVD was considered mild. However, pathological findings, echocardiography, X-ray examination and ECG revealed severe fibrosis and disruption of the myocardium (Fig. 1).

There were significant increases of $\mathrm{cHCO}_{3}, \mathrm{pCO}_{2}$ and the $\mathrm{Na} / \mathrm{Cl}$ ratio in the VD group (Fig. 2A-C). VD is commonly observed in elderly monkeys as well as in humans. These results suggest that metabolic and respiratory acidosis is associated with VD, and these symptoms have been reported in human VD [17]. This clearly demonstrates the effects on arterial blood gas in CVD, and the results of this study are highly applicable to disease diagnosis. Specifically, there are no reports of $\mathrm{cHCO}_{3}$ increases related to $\mathrm{CVD}$ in macaques, thus, this result will be important for the management and veterinary care of nonhuman primates.

Analysis of the CBC parameters indicated differences of several erythrocyte indices among the CVD subgroups. Significant differences in RDW were observed between the control and VD groups (Fig. 3A). Additionally, there were significant increases in RDW and a variety of erythrocyte indices. MCV, MCH and MCHC were increased in the DCM group, which suggested the presence of macrocytosis. Additionally, there are significant decreases of MCHC in the VD group. The MCHC decreases indicate decline in HGB, suggesting that the underlying cause of the symptoms is chronic inflammation [23].

In examinations of biochemical parameters and cardiac hormones, there were significant differences in cardiac hormone levels between the VD and DCM groups although SD value was extremely broad. Significant increases were observed in hANP and hBNP (Fig. 4A and 4B), and increases in these hormones due to cardiomyopathy have been confirmed [18]. These findings are likely to relate to the physiological mechanism of these hormones, in which myocardial injury stimulates their production and release from the myocardium. Thus, cardiac hormone levels are expected to be elevated in cardiomyopathy as a result of the occurrence of myocardial damage. Furthermore, it is known that these cardiac hormones are increased in severe valvular heart disease $[21,27]$. However, since the subjects used in this study had mild CVD, it is not unexpected that the cardiac hormone values did not fluctuate greatly. Scoring of the abnormal level is preferable to investigate, because the VD and DCM group showed bipolar data. In humans and dogs, methods of scoring the grade of CVD based on clinical symptoms and clinical laboratory findings have already been proposed and used in the classification by the New York Heart Association (NYHA) and International Small Animal Cardiac. Health Council (ISACHC) [3, 19]. However, it was difficult to evaluate exercise intolerance, because all monkeys used in this study were kept in the cage, and clinical symptoms were not observed. Also, there are no reports that scoring the abnormal level of CVD in cynomolgus monkeys. Therefore, it will be important to consider each stage of CVD in future research.

In conclusion, the use of several blood tests in combination revealed a wealth of information regarding CVD in nonhuman primates relative to behavioral observations alone. Animals with CVD easily change their condition by anesthesia and surgical invasion. In this study, CVD group showed a drastic change in arterial blood gas and various blood biochemical tests. It was suggested that the combination of arterial blood gas and other biochemical tests are useful for CVD affected monkeys in laboratory. Careful handling is necessary to management of CVD affected monkeys as an animal welfare. Pay attention to arterial blood gas and proper respond to their condition are especially important for science research because it reflect the circulatory dynamics and respiratory conditions. Proper care makes it possible to carry out research that is safer and less invasive, and consequence better information will be given. Laboratory primates are precious resources, thus, the early detection of symptoms of diseases and disorders is imperative. The use of a combination of blood tests, including arterial blood gas, allowed the comprehensive management of animals to the same level as a technical exam. This study reports that specific blood test results were attributable to CVD. The results thus obtained will serve as the foundation for disease control in developing and breeding monkeys, as well as having utility as a substitute for human medicine and further development of human medical care.

ACKNOWLEDGMENTS. We wish to thank Hiromi Ogawa for the handling and care of the monkeys used in this study. We are grateful to Keiko Ohto and Chieko Ohno for their excellent technical assistance. This work was supported by JSPS KAKENHI Grant Numbers 24615009 and 15K07789, as well as grants from the Japan Agency for Medical Research and Development (AMED) under Grant Number JP18ak0101047h0003. 


\section{REFERENCES}

1. Ageyama, N., Seki, Y., Muneyuki, K., Kandori, A., Tsukada, K. and Terao, K. 2007. Application of magnetocardiography for non-human primate arrhythmia models. J. Jpn. Biomagnetism Bioelectromagnetics Soc. 20: 90-91.

2. Bashuda, H., Kimikawa, M., Seino, K., Kato, Y., Ono, F., Shimizu, A., Yagita, H., Teraoka, S. and Okumura, K. 2005. Renal allograft rejection is prevented by adoptive transfer of anergic T cells in nonhuman primates. J. Clin. Invest. 115: 1896-1902. [Medline] [CrossRef]

3. Choi, B. S., Moon, H. S., Seo, S. H. and Hyun, C. 2017. Evaluation of serum cystatin-C and symmetric dimethylarginine concentrations in dogs with heart failure from chronic mitral valvular insufficiency. J. Vet. Med. Sci. 79: 41-46. [Medline] [CrossRef]

4. Danese, E., Lippi, G. and Montagnana, M. 2015. Red blood cell distribution width and cardiovascular diseases. J. Thorac. Dis. 7: E402-E411. [Medline]

5. Felker, G. M., Allen, L. A., Pocock, S. J., Shaw, L. K., McMurray, J. J., Pfeffer, M. A., Swedberg, K., Wang, D., Yusuf, S., Michelson, E. L., Granger C. B., CHARM Investigators. 2007. Red cell distribution width as a novel prognostic marker in heart failure: data from the CHARM Program and the Duke Databank. J. Am. Coll. Cardiol. 50: 40-47. [Medline] [CrossRef]

6. Goto, Y., Hiramatsu, Y., Ageyama, N., Sato, S., Kanemoto, S., Sato, Y. and Sakakibara, Y. 2014. Cardiopulmonary bypass induces recruitment of bone marrow-derived leukocytes to the lungs in monkeys. Ann. Thorac. Surg. 97: 617-622. [Medline] [CrossRef]

7. Hom, G. J., Bach, T. J., Carroll, D., Forrest, M. J., Mariano, M. A., Trainor, C. E., Wang, P. R. and MacIntyre, D. E. 1999. Comparison of Cardiovascular Parameters and/or Serum Chemistry and Hematology Profiles in Conscious and Anesthetized Rhesus Monkeys (Macaca mulatta). Contemp. Top. Lab. Anim. Sci. 38: 60-64. [Medline]

8. Honjo, S. 1985. The Japanese Tsukuba Primate Center for Medical Science (TPC): an outline. J. Med. Primatol. 14: 75-89. [Medline]

9. Honjo, S. 1986. Guiding Principles for animal experiments using nonhuman primates. Primate Rep. 2: 111-113. [CrossRef]

10. Institute of Laboratory Animal Research. 2011. Guide for the Care and Use of Laboratory Animals. National Academies Press, Washington, D.C.

11. Kanda, Y. 2013. Investigation of the freely available easy-to-use software 'EZR' for medical statistics. Bone Marrow Transplant. 48: 452-458. [Medline] [CrossRef]

12. Kim, E. B., Susan, M. B., Scott, B. and Heddwen, L. B. 2006. Ganong's Review of Medical Physiology, 24th ed., McGraw-Hill Education, New York.

13. Koie, H., Ageyama, N., Ono, F., Kanayama, K., Sakai, T. and Sankai, T. 2005. Echocardiographic diagnosis of muscular ventricular septal defect in a cynomolgus monkey (Macaca fascicularis). Contemp. Top. Lab. Anim. Sci. 44: 26-28. [Medline]

14. Lee, J. I., Hong, S. H., Lee, S. J., Kim, Y. S. and Kim, M. C. 2003. Immobilization with ketamine HCl and tiletamine-zolazepam in cynomolgus monkeys. J. Vet. Sci. 4: 187-191. [Medline]

15. Lee, J. I., Shin, J. S., Lee, J. E., Jung, W. Y., Lee, G., Kim, M. S., Park, C. G. and Kim, S. J. 2012. Reference values of hematology, chemistry, electrolytes, blood gas, coagulation time, and urinalysis in the Chinese rhesus macaques (Macaca mulatta). Xenotransplantation 19: 244-248. [Medline] [CrossRef]

16. Mazzotta, E., Guglielmini, C., Menciotti, G., Contiero, B., Baron Toaldo, M., Berlanda, M. and Poser, H. 2016. Red blood cell distribution width, hematology, and serum biochemistry in dogs with echocardiographically estimated precapillary and postcapillary pulmonary arterial hypertension. J. Vet. Intern. Med. 30: 1806-1815. [Medline] [CrossRef]

17. Mrsic, Z., Hopkins, S. P., Antevil, J. L. and Mullenix, P. S. 2018. Valvular Heart Disease. Prim. Care 45: 81-94. [Medline] [CrossRef]

18. Mukoyama, M., Nakao, K., Hosoda, K., Suga, S., Saito, Y., Ogawa, Y., Shirakami, G., Jougasaki, M., Obata, K., Yasue, H., Kambayashi, Y., Inouye, K. and Imura, H. 1991. Brain natriuretic peptide as a novel cardiac hormone in humans. Evidence for an exquisite dual natriuretic peptide system, atrial natriuretic peptide and brain natriuretic peptide. J. Clin. Invest. 87: 1402-1412. [Medline] [CrossRef]

19. Naderi, N., Heidarali, M., Barzegari, F., Ghadrdoost, B., Amin, A. and Taghavi, S. 2015. Hormonal profile in patients with dilated cardiomyopathy. Res. Cardiovasc. Med. 4: e27631. [Medline] [CrossRef]

20. Nakayama, S., Koie, H., Kanayama, K., Katakai, Y., Ito-Fujishiro, Y., Sankai, T., Yasutomi, Y. and Ageyama, N. 2017. Establishment of reference values for complete blood count and blood gases in cynomolgus monkeys (Macaca fascicularis). J. Vet. Med. Sci. 79: 881-888. [Medline] [CrossRef]

21. Sharma, V., Stewart, R. A., Lee, M., Gabriel, R., Van Pelt, N., Newby, D. E. and Kerr, A. J. 2016. Plasma brain natriuretic peptide concentrations in patients with valvular heart disease. Open Heart 3: e000184. [Medline] [CrossRef]

22. Schuurman, H. J. and Smith, H. T. 2005. Reference values for clinical chemistry and clinical hematology parameters in cynomolgus monkeys. Xenotransplantation 12: 72-75. [Medline] [CrossRef]

23. Tonelli, M., Sacks, F., Arnold, M., Moye, L., Davis, B., Pfeffer M., for the Cholesterol and Recurrent Events (CARE) Trial Investigators. 2008. Relation between red blood cell distribution width and cardiovascular event rate in people with coronary disease. Circulation 117: $163-168$. [Medline] [CrossRef]

24. Venco, L., Bertazzolo, W., Giordano, G. and Paltrinieri, S. 2014. Evaluation of C-reactive protein as a clinical biomarker in naturally heartworminfected dogs: a field study. Vet. Parasitol. 206: 48-54. [Medline] [CrossRef]

25. Washington University School of Medicine. D. H. Cooper, A. J. Krainik, S. J. Lubner, H. EL. Reno. 2007. The Washington Manual of Medical Therapeutics. 32nd ed., Lippincott Williams \& Wilkins, Pennsylvania.

26. Yoshioka, T., Ageyama, N., Shibata, H., Yasu, T., Misawa, Y., Takeuchi, K., Matsui, K., Yamamoto, K., Terao, K., Shimada, K., Ikeda, U., Ozawa, K. and Hanazono, Y. 2005. Repair of infarcted myocardium mediated by transplanted bone marrow-derived CD34+ stem cells in a nonhuman primate model. Stem Cells 23: 355-364. [Medline] [CrossRef]

27. Yoshimura, M., Yasue, H., Okumura, K., Ogawa, H., Jougasaki, M., Mukoyama, M., Nakao, K. and Imura, H. 1993. Different secretion patterns of atrial natriuretic peptide and brain natriuretic peptide in patients with congestive heart failure. Circulation 87: 464-469. [Medline] [CrossRef]

28. Yuki, Y., Nochi, T., Harada, N., Katakai, Y., Shibata, H., Mejima, M., Kohda, T., Tokuhara, D., Kurokawa, S., Takahashi, Y., Ono, F., Kozaki, S., Terao, K., Tsukada, H. and Kiyono, H. 2010. In vivo molecular imaging analysis of a nasal vaccine that induces protective immunity against botulism in nonhuman primates. J. Immunol. 185: 5436-5443. [Medline] [CrossRef] 